DOI: 10.1002/aelm.201800287

Article type: Full Paper

\title{
Robust Macroscopic Polarization of Block Copolymer-Templated Mesoporous Perovskite-Type Thin-Film Ferroelectrics
}

\section{Lidija Androš Dubraja, * Robert Kruk, and Torsten Brezesinski*}

Dr. L. Androš Dubraja, Dr. R. Kruk, Dr. T. Brezesinski

Institute of Nanotechnology, Karlsruhe Institute of Technology, Hermann-von-Helmholtz-

Platz 1, 76344 Eggenstein-Leopoldshafen, Germany

E-mail: lidija.andros@irb.hr; torsten.brezesinski@kit.edu

Dr. L. Androš Dubraja

Ruđer Bošković Institute, Bijenička cesta 54, 10000 Zagreb, Croatia

Keywords: sol-gel chemistry, polymer templating, lithium niobate, lithium tantalate, ferroelectricity

Ferroelectrics play an important role in various applications, from electronics to mechanics, optics, and biomedicine. Herein, the preparation of a series of block copolymer-templated mesostructured (lead-free) oxide ferroelectrics is described. Distorted perovskite $\mathrm{LiNbO}_{3}$, $\mathrm{LiTaO}_{3}$, and solid solution $\mathrm{LiNbO}_{3}-\mathrm{LiTaO}_{3}$ are produced as single-phase thin films of good quality by the dip-coating method using an evaporation-induced self-assembly process. They are investigated by a combination of electron microscopy, X-ray diffraction and scattering, Xray photoelectron spectroscopy, and time-of-flight secondary ion mass spectrometry. Thermal treatment at $\geq 600{ }^{\circ} \mathrm{C}$ is required to initiate crystallization. Both the pore ordering and thermal stability increase with increasing tantalum content. Ferroelectric testing through dynamic and remanent polarization experiments at ambient conditions confirm the uniformity and purity of the $\mathrm{LiNbO}_{3}$ thin-film system. Results from positive-up and negative-down test measurements reveal a stable switching polarization of $2 \mu \mathrm{C} \mathrm{cm}^{-2}$, with a coercive field of $50 \mathrm{kV} \mathrm{cm}^{-1}$.

Taken together, the lithium niobium and tantalum oxides prepared in this work are rare examples of sol-gel derived perovskite-type materials with an ordered mesoporous morphology. Because of the spontaneous electrical polarization observed for $\mathrm{LiNbO}_{3}$, such 


\section{WILEY-VCH}

block copolymer-templated thin films might pave the way for the development of a new class of 3D nanocomposite ferroics.

\section{Introduction}

In recent years, significant efforts have been devoted to developing lead-free or, in other words, environmentally more friendly ferroelectric materials. ${ }^{[1]}$ However, the search for viable alternatives to e.g. lead zirconate titanate (PZT), which is one of the best studied and most widely used electroceramics, has proven challenging. This is due in part to the superior performance of lead-based ferroelectrics and their prevalence in applications such as memory devices, actuators, and sensors to name a few. ${ }^{[2,3]}$ Note that there is a limited number of leadfree materials that exhibit room-temperature ferroelectric ordering and hold promise for use in the micro- and nanoelectronics area. ${ }^{[4,5]}$

$\mathrm{ABO}_{3}$ perovskites are an ubiquitous class of inorganics with many attractive properties and they are currently by far the most important ferroelectrics. ${ }^{[5]}$ Apart from $\mathrm{PZT}\left(\right.$ or $\left.\mathrm{PbTiO}_{3}\right)$ and $\mathrm{BaTiO}_{3}$, which can be considered prototype ferroelectrics, ${ }^{[6]}$ in particular niobium- and tantalum-based perovskites apparently exhibit interesting and competitive properties. ${ }^{[1,7-10]}$ Among them is lithium niobate $\left(\mathrm{LiNbO}_{3}\right)$, a material with a distorted perovskite structure and comparatively high Curie temperature $\left(T_{\mathrm{c}} \approx 1480 \mathrm{~K}\right)$.

Ferroelectric $\mathrm{LiNbO}_{3}$ crystallizes in the trigonal space group $R 3 c$. Unlike in the hightemperature paraelectric phase (space group $R \overline{3} c$ ), strong internal elastic forces result in atom displacement (from the centrosymmetric position). The thus created dipoles organize themselves into domains, thereby giving rise to robust spontaneous polarization. ${ }^{[11,12]}$ Lithium tantalate $\left(\mathrm{LiTaO}_{3}\right)$ shows analogous behavior. However, the ferroelectric-to-paraelectric transition occurs at a much lower temperature $\left(T_{\mathrm{c}} \approx 970 \mathrm{~K}\right)$ and the overall properties appear to be more sensitive to variations in stoichiometry. ${ }^{[13]}$ 


\section{WILEY-VCH}

Despite being promising candidates for replacement of lead-based ferroelectrics in various fields of application, at present, there is a lack of reliable data, especially from remanent polarization experiments. For example, the spontaneous polarization of $\mathrm{LiNbO}_{3}$ single crystals at room temperature was estimated from pyroelectric measurements to be at least 50 $\mu \mathrm{C} \mathrm{cm}^{-2} \cdot{ }^{[14]}$ Later, dynamic polarization results obtained on $Z$-cut, single-domain crystals revealed a spontaneous polarization of around $80 \mu \mathrm{C} \mathrm{cm}^{-2}$ and further the presence of relatively large internal fields $\left(20-30 \mathrm{kV} \mathrm{cm}^{-1}\right)$. The latter were shown to originate from point (dipolar) defects due to nonstoichiometry and to strongly affect the magnitude of the switching field. ${ }^{[15,16]}$

Apparently, materials that exhibit high overall crystallinity and are ideally free of impurities and defects in structure are required to achieve optimum ferroelectric properties. In practice, (epitaxial) films, single crystals, and polycrystalline ceramics are used for ferroelectric applications..$^{[1,2,4-7,13-16]}$ However, in particular high-temperature (reaction and/or densification) treatments may be detrimental to the performance, mainly because of $\mathrm{Li}_{2} \mathrm{O}$ loss and the associated changes in composition. Several low- and medium-temperature techniques have been shown suitable for producing $\mathrm{LiNbO}_{3}$ and $\mathrm{LiTaO}_{3}$ thin films, including chemical vapor deposition, ${ }^{[17]}$ laser ablation, ${ }^{[18]}$ pulsed laser deposition, ${ }^{[19]}$ atomic layer deposition, ${ }^{[20]}$ molecular beam epitaxy, ${ }^{[21]}$ and radio frequency sputtering. ${ }^{[22]}$ Nevertheless, most of these techniques are elaborate and relatively expensive.

For the majority of applications in the electronic industry, high quality thin films are required. Besides, there is a continuous demand for device miniaturization (i.e. aiming at making the devices smaller in size and lighter in weight with improved performance and functionality). ${ }^{[23]}$ One way to increase functionality is to incorporate nanoscale features in ferroelectric materials. ${ }^{[3]}$ Porous electroceramics typically exhibit lower polarizability than their dense counterparts, but they offer much more possibilities for structuring - especially when it comes to producing multifunctional and multicomponent systems - and tuning/tailoring of 


\section{WILEY-VCH}

properties. ${ }^{[24]}$ Recently, it was shown that inhomogeneous field distribution due to the presence of pores is key to various functional properties. ${ }^{[25]}$

Chemical solution deposition routes, which are generally low cost and allow for easy fabrication using sol-gel processes, offer the possibility of creating 3D porous nanostructures through co-assembly strategies. ${ }^{[26-34]}$ However, producing ternary or even more complex oxides with both a well-defined mesoporous morphology and highly crystalline walls is far from being easy, which is why there are only few literature reports on such thin-film ferroelectrics. ${ }^{[35-37]}$

Here, we report on the evaporation-induced self-assembly (EISA) synthesis and characterization of lead-free ferroelectrics, specifically perovskite-type $\mathrm{LiNbO}_{3}, \mathrm{LiTaO}_{3}$, and solid solution $\mathrm{LiNbO}_{3}-\mathrm{LiTaO}_{3}{ }^{[38-40]}$ The materials were prepared in the form of cubic mesoporous thin films using a well-established block copolymer as structure-directing agent. Chemical and structural data obtained from different techniques such as synchrotron-based grazing incidence small-angle X-ray scattering (GISAXS), grazing incidence X-ray diffraction (GIXD), X-ray photoelectron spectroscopy (XPS), and time-of-flight secondary ion mass spectrometry (ToF-SIMS) demonstrate the homogeneity and uniformity of the deposited films on different length scales. These results are further confirmed by (macroscopic) dynamic and remanent polarization measurements, which in addition provide clear evidence that the EISA process offers fine control over both nanoscale structure and stoichiometry.

\section{Results and Discussion}

The mesoporous thin films were prepared by the dip-coating method from mixed-solvent solgel solutions containing glacial acetic acid as complexing agent and a KRATON LIQUIDbased amphiphilic block copolymer as structure-directing agent. ${ }^{[41]}$ We note that acetic acid slows down the hydrolysis and condensation reactions of the alkoxide precursors, thereby 


\section{WILEY-VCH}

ensuring stabile deposition conditions. More importantly, the block copolymer employed in this work allows producing architectures with relatively large pores and thick walls; consequently, there is a higher chance of retaining the nanoscale porosity and ordering during the crystallization process. ${ }^{[42-48]}$

The pore structure was studied by a combination of electron microscopy and GISAXS.

Figure 1 shows scanning (SEM) and transmission electron microscopy (TEM) images as well as electron diffraction (ED) data obtained on $\mathrm{LiNbO}_{3}$ and $\mathrm{LiTaO}_{3}$ thin films heated at temperatures between 500 and $700{ }^{\circ} \mathrm{C}$. Samples heated at $500{ }^{\circ} \mathrm{C}$ are fully amorphous. However, aging treatments of $<1$ min at $600{ }^{\circ} \mathrm{C}$ for $\mathrm{LiNbO}_{3}$ and $700{ }^{\circ} \mathrm{C}$ for $\mathrm{LiTaO}_{3}$ are sufficient to initiate crystallization of the inorganic walls, as indicated by the ED patterns (see insets in Figure 1). ED also demonstrates that both materials adopt a trigonal structure, which can be described as a distorted perovskite. As is evident from Figure 1, $\mathrm{LiTaO}_{3}$ displays better pore ordering than $\mathrm{LiNbO}_{3}$. The same holds true for mixed $\mathrm{LiNbO}_{3}-\mathrm{LiTaO}_{3}$ thin films (see top-view SEM images before and after crystallization in Figure S1), thus indicating that the niobium and tantalum alkoxide precursors used exhibit different behavior and reactivity. The electron microscopy images further reveal that the crystallization is associated with some restructuring of the cubic pore-solid architectures. The initially $18-20 \mathrm{~nm}$ pores (amorphous state) shrink while the walls increase in size, and the nanoscale structures tend to look more wormlike. ${ }^{[4]}$ This structural transformation is even more apparent at higher heating temperatures, as exemplified for $\mathrm{LiNbO}_{3}$, and is likely a result of grain growth or coarsening. Nevertheless, the pore networks do not collapse, and the films remain free of major defects such as microcracks (see also low-magnification top-view SEM images in Figure S2). Taken together, we conclude that the stable crystallite size is $>>10 \mathrm{~nm}$ and there is a sweet spot in terms of heating temperature, where the materials have simultaneously reasonably high levels of crystallinity and periodicity. 


\section{WILEY-VCH}

Ex situ GISAXS patterns of $\mathrm{LiNbO}_{3}, \mathrm{LiTaO}_{3}$, and mixed $\mathrm{LiNbO}_{3}-\mathrm{LiTaO}_{3}$ thin films in amorphous and crystalline states are shown in Figure $\mathbf{2}$ and S3. First of all, they corroborate the imaging results. In fact, $\mathrm{LiTaO}_{3}$ exhibits both the highest degree of pore ordering (cubic symmetry) of all three materials and the strongest preferred orientation of the mesostructure to the substrate. The former is reflected in the slightly smaller in-plane repeat distances (more closed-packed structure), and the latter is apparent from the presence of scattering spots instead of a diffuse elliptical ring seen for $\mathrm{LiNbO}_{3}$. Besides, GISAXS indicates volume contractions of almost $80 \%$. The primary reason for the unidirectional film contraction (note there is virtually no in-plane contraction) is the condensation of the inorganic framework, which seems to be largely completed after aging of $12 \mathrm{~h}$ at $300{ }^{\circ} \mathrm{C}$. As expected, because of the morphological anisotropy, only the scattering in the in-plane direction is retained after crystallization at heating temperatures of $\geq 600{ }^{\circ} \mathrm{C}$. This finding provides profound evidence that the nanoscale structures are partly retained, which agrees well with the electron microscopy data discussed before. In addition, the results with SEM and GISAXS clearly demonstrate that the thermal stability of the sol-gel derived materials increases with increasing tantalum content.

Both the microstructure and composition were analyzed by GIXD, XPS, and ToF-SIMS, respectively. Figure 3a depicts GIXD data obtained on a mesoporous $\mathrm{LiNbO}_{3}$ thin film after heating at $650{ }^{\circ} \mathrm{C}$ along with a Rietveld refinement of the pattern. The analysis demonstrates that the material crystallizes in the space group $R 3 c$, with lattice parameters $a, b=5.1342(2)$ $\AA$ and $c=13.8123(2) \AA$, in agreement with the ICSD reference code 28294 for ferroelectric $\mathrm{LiNbO}_{3}$. Details of the Rietveld refinement results are provided in Table S1. The calculated crystallite size is $(20 \pm 1) \mathrm{nm}$, which is consistent with the wall thickness from SEM imaging. Wide-angle X-ray diffraction (WAXD) data collected in Bragg-Brentano geometry around the main reflection at $23.7^{\circ} 2 \theta$ of mesoporous $\mathrm{LiNbO}_{3}$, mixed $\mathrm{LiNbO}_{3}-\mathrm{LiTaO}_{3}$, and $\mathrm{LiTaO}_{3}$ thin films heated at 600, 650, and $700{ }^{\circ} \mathrm{C}$, respectively, are shown in Figure S4. The (012) 


\section{WILEY-VCH}

reflection clearly shifts toward higher angles with increasing tantalum content, thereby confirming solid solution behavior in the case of $\mathrm{LiNbO}_{3}-\mathrm{LiTaO}_{3}\left(\mathrm{i} . e . \mathrm{LiNb}_{0.5} \mathrm{Ta}_{0.5} \mathrm{O}_{3}\right.$ ). In addition, the onset crystallization temperature of $\mathrm{LiNb}_{0.5} \mathrm{Ta}_{0.5} \mathrm{O}_{3}$ is found to lie between that of $\mathrm{LiNbO}_{3}$ and $\mathrm{LiTaO}_{3}$.

The film composition, including bonding configuration and oxidation state, was investigated via XPS. Figure S5 depicts spectra of the Nb3d, Ta4f, O1s, and Li1s regions along with the results from curve fitting. The $\mathrm{Nb3d}$ data can be deconvoluted into two peaks (with a 2:3 area ratio and the same full width at half maximum) at $209.8 \mathrm{eV}\left(3 \mathrm{~d}_{3 / 2}\right)$ and $207.1 \mathrm{eV}\left(3 \mathrm{~d}_{5 / 2}\right)$, which is indicative of the oxidation state $5+$. The O1s spectrum also shows two peaks, with the strongest component at $530.1 \mathrm{eV}$ being lattice oxygen. The minor peak at $531.6 \mathrm{eV}$ can be assigned to surface hydroxy groups and likely to some C-O type species as well. The Li1s peak is found at a binding energy of around $55 \mathrm{eV}$. However, the lithium content (Li: $\mathrm{Nb}$ ratio) cannot be determined with high accuracy because of partial overlapping with other niobium signals such as $\mathrm{Nb} 4 \mathrm{~s}$ at $60.3 \mathrm{eV}$. Similar results were obtained for the mesoporous $\mathrm{LiTaO}_{3}$ thin films.

Finally, ToF-SIMS depth profiling was done to study the distribution of lithium and niobium through the film thickness. As can be seen from the profile in Figure 3b, both the ${ }^{7} \mathrm{Li}^{+}$and ${ }^{93} \mathrm{Nb}^{+}$signals are rather stable. Taking into account the XRD and XPS data, this demonstrates that the films are homogeneous and well-defined not only structurally, but also compositionally and the volatility of lithium or, more rigorously, of $\mathrm{Li}_{2} \mathrm{O}$ is not an issue. Minor variations are only observed for ${ }^{93} \mathrm{Nb}^{+}$at the top surface and near the substrate interface, with the latter most likely being due to the different chemical environment. Besides, it can be seen that the block copolymer structure-directing agent is fully combusted after heating in air at temperatures of $\geq 600^{\circ} \mathrm{C}$. This result establishes that the nanoscale porosity is open and persists throughout the bulk of the material. 


\section{WILEY-VCH}

Because high crystallinity is essential to achieve optimum ferroelectric properties, mesoporous $\mathrm{LiNbO}_{3}$ on $\mathrm{Nb}$-doped $\mathrm{SrTiO}_{3}(\mathrm{STO}: \mathrm{Nb})$ substrate heated at $650{ }^{\circ} \mathrm{C}$ was used for the macroscopic polarization measurements. The ferroelectric testing was primarily performed on $250 \mathrm{~nm}$-thick films with $50 \mathrm{~nm}$ Au top electrodes at ambient conditions. We note that a film thickness of $>200 \mathrm{~nm}$ was sufficient to prevent short circuiting during $\mathrm{Au}$ sputter deposition.

The majority of literature studies report data from dynamic measurements which, however, may be strongly affected by extrinsic artifacts such as leakage current and dielectric polarization. A convenient way to "extract" only the remanent (switching) polarization is via the positive-up and negative-down (PUND) test. ${ }^{[50]}$ In general, PUND measurements rely on a pulse train of two consecutive positive and then two negative triangle voltage pulses of same amplitude and delay time, thus allowing for subtraction of the non-switching (volatile) components (Scheme S1). ${ }^{[51]}$

A series of dynamic and remanent polarization experiments for different switching frequencies and voltages were performed in search of optimal conditions with regard to polarization. Ferroelectric saturation was reached when operating in a voltage range between 2 and 3 V. Larger voltages led to electrical breakdown, even for high frequencies or, in other words, short cycle times. Figure 4a depicts a representative polarization $(P)$ vs. electric field (E) curve obtained at $10 \mathrm{~Hz}$ and for a maximum applied electric field of $120 \mathrm{kV} \mathrm{cm}^{-1}$, providing values of $\approx 10 \mu \mathrm{C} \mathrm{cm}{ }^{-2}$ for $P_{\mathrm{s}}$ (saturation/spontaneous polarization) and $\approx 8 \mu \mathrm{C} \mathrm{cm} \mathrm{cm}^{-2}$ for $P_{\mathrm{r}}$ (remanent polarization), with a coercive field $\left(E_{\mathrm{c}}\right)$ of $\approx 60 \mathrm{kV} \mathrm{cm}^{-1}$. The maximum dynamic polarization is found to increase with decreasing frequency (Figure S6). This kind of time dependency is a fingerprint of leakage current and/or dielectric contribution to the charging process.

In the dielectric polarization, the charging current and the resulting maximum polarization charge are dependent on the characteristic time given by the product of resistance and 


\section{WILEY-VCH}

capacitance of the tested device. If the charging time is shorter than the characteristic time, the polarization is not reaching its maximum and is getting smaller with increasing frequency (or vice versa with decreasing frequency). In the case of current leakage, the frequency dependency is straightforward: the longer the measurement time (lower frequency), the more artificial charge accumulation is observed. Therefore, in order to get rid of the non-switching contributions to obtain the genuine ferroelectric polarization, the PUND testing was performed on the mesoporous $\mathrm{LiNbO}_{3}$ samples.

The remanent hysteresis loop measured at $10 \mathrm{~Hz}$ is depicted in Figure $\mathbf{4 b}$. As can be seen, it is more square-like, with maxima of the charging currents at $E_{\mathrm{c}}$. Data analysis indicated that $P_{\mathrm{s}} \sim P_{\mathrm{r}} \approx 2 \mu \mathrm{C} \mathrm{cm}^{-2}$ and $E_{\mathrm{c}} \approx 50 \mathrm{kV} \mathrm{cm}^{-1}$. Unlike in the case of dynamic measurements, where the polarization increased with decreasing frequency, the remanent polarization is very similar for 10 and $300 \mathrm{~Hz}$, in line with expectations (Figure S7). The fact that $P_{\mathrm{r}}$ obtained in dynamic mode $\left(10 \mathrm{~Hz}\right.$ data) is roughly four times larger demonstrates that the $\mathrm{LiNbO}_{3}$ thin films exhibit relatively large dielectric (paraelectric) capacitances and are also prone to electrical leakage. However, this is not very surprising, especially under ambient measurement conditions, given that the material is both nanocrystalline and highly porous. Nevertheless, interestingly, there is a striking similarity to the ferroelectric properties of near-stoichiometric $\mathrm{LiNbO}_{3}$ crystals. ${ }^{[15]}$ In particular, the switching field $\left(\approx 40 \mathrm{kV} \mathrm{cm}^{-1}\right)$ agrees well with the value of $E_{\mathrm{c}}$ measured in the presented work. Considering that, and the fact that $E_{\mathrm{c}}$ for $Z$-cut single crystals of $\mathrm{LiNbO}_{3}$ and $\mathrm{LiTaO}_{3}$ was shown to be strongly dependent on the $\mathrm{Li}$ nonstoichiometry, it is reasonable to conclude that the ferroelectric domain switching in the sol-gel derived thin films is largely determined by their chemical composition, despite the different morphology and grain size. This thus confirms that the EISA process is a very powerful tool for the preparation of well-defined mesoporous oxides, offering precise control over both the nanoscale structure and the stoichiometry. 


\section{WILEY-VCH}

Because the interface between the ferroelectric material and the electrode(s) plays an important role in the physical behavior of the system, the overall performance of ferroelectric capacitors depends to some degree also on the type of top and bottom contacts used. ${ }^{[52-54]}$ Oxide-metal interfaces may lead to undesired effects such as formation of Schottky junctions (reflected in asymmetry of the hysteresis loops), caused by leakage currents for positive voltages and blocking in reversed mode. ${ }^{[54]}$ On the other hand, the use of only oxide electrode capacitors was shown e.g. for $\mathrm{BaTiO}_{3}$ to result in better reliability properties. ${ }^{[53]}$ For that reason, in the present work, we also tested indium tin oxide (ITO) as a potential oxide top electrode. Representative $P-E$ loops for different switching frequencies obtained on mesoporous $\mathrm{LiNbO}_{3}$ thin films on STO:Nb substrate with ITO top contacts are depicted in Figure 4c and S8. As is evident, the measured dynamic hysteresis loops are more slanted and narrowed, resembling rather paraelectric characteristics. However, small bumps in the current response curve are observed, which can be interpreted as indicating the presence of ferroelectric polarization. Although the oxide-oxide interface was expected to eliminate some of the parasitic contributions, the use of ITO resulted in much more pronounced paraelectric behavior than in the configuration with $\mathrm{Au}$. A rough estimation on the dielectric constant gave values of $>1000$, thus confirming the paraelectric nature of the mesoporous thin films with ITO top electrodes.

Direct comparison with data on ferroelectric properties of $\mathrm{LiNbO}_{3}$ in the literature is difficult as most studies only report results from dynamic measurements, typically leading to an overestimation of polarization. The polarization values obtained on single-domain $\mathrm{LiNbO}_{3}$ crystals are apparently considerably larger $\left(P_{\mathrm{s}} \approx 80 \mu \mathrm{C} \mathrm{cm}^{-2}\right)$; however, linear capacitances and artifacts from leakage were not considered. ${ }^{[15,16]}$ Nevertheless, compared with thin films grown by atomic layer deposition $\left(P_{\mathrm{r}} \approx 0.4 \mu \mathrm{C} \mathrm{cm}^{-2}\right.$; note that the measurements were also performed in dynamic mode), significant improvements in ferroelectric behavior (i.e. polarizability, remanence etc.) have been achieved here. ${ }^{[20]}$ Taken together, our research data 


\section{WILEY-VCH}

establish that, in the presence of an applied electric field, block copolymer-templated mesostructured $\mathrm{LiNbO}_{3}$ thin-film ferroelectrics, somewhat counter-intuitively, exhibit robust macroscopic polarization at room temperature.

\section{Conclusion}

Perovskite-type $\mathrm{LiNbO}_{3}, \mathrm{LiTaO}_{3}$, and solid solution $\mathrm{LiNbO}_{3}-\mathrm{LiTaO}_{3}$ were successfully prepared, for the first time, as continuous cubic mesoporous films by solution-phase coassembly of acetate and alkoxide precursors with a block copolymer structure-directing agent using the dip-coating method. Stable deposition conditions were achieved by addition of excess glacial acetic acid to the mixed-solvent sol-gel solutions. Thermal treatment at $\geq 600{ }^{\circ} \mathrm{C}$ was required to initiate crystallization of the initially amorphous pore walls, and progressive crystallization appeared to be the main reason for the decrease in pore ordering and the apparent formation of wormlike morphologies. Structural characterization confirmed both the trigonal ferroelectric structures in the space group $R 3 c$ and the single phase nature of the materials. Even more importantly, the films were not only structurally but also compositionally uniform throughout, making them good model materials.

Room temperature polarization-switching experiments demonstrated that the block copolymer-templated mesoporous $\mathrm{LiNbO}_{3}$ thin films on $\mathrm{SrTiO}_{3}: \mathrm{Nb}$ substrate exhibit nonnegligible contributions from dielectric polarization and electrical leakage. However, positiveup and negative-down test measurements revealed a stable switching polarization of around 2 $\mu \mathrm{C} \mathrm{cm}^{-2}$, with a coercive field of $50 \mathrm{kV} \mathrm{cm}^{-1}$. Interestingly, the switching field was in the same range as that observed for near-stoichiometric $\mathrm{LiNbO}_{3}$, while it was significantly lower as compared to nonstoichiometric Z-cut, single-domain crystals. This indicates the intriguing possibility that the ferroelectric polarization, which is a bulk property, can be tailored to some degree by carefully controlling the precursor amounts used in the synthesis. Unfortunately, 


\section{WILEY-VCH}

attempts to eliminate some of the non-remanent polarization contributions by using oxide instead of metal top electrodes failed.

Taken together, the integration of 3D nanoscale porosity with macroscopic ferroelectric polarization might pave the way for the development of mesostructured two- or multiphase nanoferroics to explore new functionalities and device architectures.

\section{Experimental Section}

Materials: Lithium acetate (99.95\%), niobium(V) ethoxide (99.95\%), tantalum(V) butoxide (99.99\%), absolute ethanol (99.9\%), 2-methoxyethanol (99.5\%), and glacial acetic acid $(99.9985 \%)$ were obtained from commercial sources and used as received.

$\mathrm{H}\left[\left(\mathrm{CH}_{2} \mathrm{CH}_{2}\right)_{0.67}\left(\mathrm{CH}_{2} \mathrm{CHCH}_{2} \mathrm{CH}_{3}\right)_{0.33}\right]_{89}\left(\mathrm{OCH}_{2} \mathrm{CH}_{2}\right)_{79} \mathrm{OH}$ (also referred to as $\mathrm{KLE}$ ) was used as structure-directing agent and porogen in the synthesis. Polished single crystal substrates of (001) orientation were purchased from both Si-Mat and SurfaceNet GmbH, including 700 $\mu$ m-thick Si and $500 \mu$ m-thick STO:Nb (0.5 wt $\% \mathrm{Nb})$. ITO $\left(\operatorname{In}_{2} \mathrm{O}_{3} / \mathrm{SnO}_{2}, 90: 10 \mathrm{wt} \%\right)$ top electrodes were prepared by direct current magnetron sputtering in Ar at room temperature and at a working pressure of $0.1 \mathrm{~Pa}$ using shadow-masks with pad sizes ranging from 0.08 to $1.36 \mathrm{~mm}^{2}$. The power supplied to the $3 \mathrm{in}$. target was set to $100 \mathrm{~W}$ and the layer thickness was controlled at $25 \mathrm{~nm}$. The same shadow-masks were also applied in the preparation of $50 \mathrm{~nm}$ thick Au top electrodes by sputter coating.

Thin-Film Synthesis: For the synthesis of $\mathrm{LiNbO}_{3}$, the block copolymer KLE (33 mg) was first dissolved by sonication in a mixed solvent of absolute ethanol $(0.80 \mathrm{~mL}), 2$ methoxyethanol $(0.65 \mathrm{~mL})$, and glacial acetic acid $(0.25 \mathrm{~mL})$. Lithium acetate $(33 \mathrm{mg})$ was then dissolved into this solution and added to a container with protective atmosphere feed containing niobium(V) ethoxide $(159 \mathrm{mg})$. The reaction mixture was stirred for a couple of minutes and subsequently used for the preparation of films by dip-coating onto different types of substrates at $25{ }^{\circ} \mathrm{C}$ and at $<10 \%$ relative humidity. After drying for $5 \mathrm{~min}$ in the chamber of 


\section{WILEY-VCH}

the dip-coater, the films were transferred to an oven at $150{ }^{\circ} \mathrm{C}$ for $1 \mathrm{~h}$ and then heated to $300{ }^{\circ} \mathrm{C}$ at $0.5^{\circ} \mathrm{C} \mathrm{min}^{-1}$, followed by aging for $12 \mathrm{~h}$. Finally, the samples were heated at $10{ }^{\circ} \mathrm{C}$ $\mathrm{min}^{-1}$ to temperatures of $\geq 600{ }^{\circ} \mathrm{C}$ to make them porous and crystalline. Both $\mathrm{LiTaO}_{3}$ and mixed $\mathrm{LiNbO}_{3}-\mathrm{LiTaO}_{3}$ thin films were prepared in the same way, but using tantalum(V) butoxide and 1:1 (molar ratio) niobium(V) ethoxide and tantalum(V) butoxide, respectively, as precursors.

Methods: SEM was performed on LEO 1530, LEO GEMINI 982, and MERLIN microscopes at 5-10 kV. TEM was performed on a CM30-ST microscope. GISAXS was performed at the German synchrotron radiation facility HASYLAB at DESY using a MarCCD area detector. The sample-to-detector distance was approx. $1820 \mathrm{~mm}$. GIXD and conventional WAXD in $\Theta$ $2 \Theta$ geometry were performed on a Bruker D8 Advance diffractometer with a Mo-K $\alpha$ radiation source and $\mathrm{X}$ 'Pert $\mathrm{PRO}$ diffractometer with a $\mathrm{Cu}-\mathrm{K} \alpha$ radiation source and an X'Celerator RTMS detector, respectively. PANalytical X'Pert HighScore Plus software was used for the Rietveld refinement of GIXD data. The diffraction profile was described using the pseudo-Voigt function and the background by the available background points. Zero shift, scale factor, half-width parameters, lattice parameters, atomic coordinates, and peak shape parameters were refined simultaneously. XPS was performed on a VersaProbe PHI 5000 Scanning ESCA Microprobe with a monochromatic Al-Ka radiation source and a hemispherical electron energy analyzer. The electron takeoff angle was set to $50^{\circ}$ and the $\mathrm{C} 1 \mathrm{~s}$ signal from adventitious hydrocarbon at $284.8 \mathrm{eV}$ was used as energy reference. ToF-SIMS was performed on a TOF.SIMS 5 instrument (IONTOF GmbH) in high-current bunched mode using $25 \mathrm{keV} \mathrm{Bi}_{3}{ }^{+}$as primary ion species $\left(100 \times 100 \mu \mathrm{m}^{2}\right.$ spot size $)$. Sputter etching was performed by means of $1 \mathrm{keV} \mathrm{O}_{2}{ }^{+}\left(200 \times 200 \mu \mathrm{m}^{2}\right.$ spot size $)$. Ferroelectric testing was done using a TF Analyzer 1000 (see Figure S9 for a photograph of a thin film in the probe station). 


\section{WILEY-VCH}

\section{Supporting Information}

Supporting Information is available from the Wiley Online Library or from the author.

\section{Acknowledgements}

Parts of this research were carried out at the light source DORIS III at DESY, a member of the Helmholtz Association (HGF). We thank Jan Perlich for assistance in using beamline BW4 and Jan Haetge, Christian Reitz, Marcus Rohnke, Ralf Witte, Alan Molinari, and Joachim Sann for assistance in materials preparation and characterization. Financial support by the German Academic Exchange Service (to L.A.D.) is gratefully acknowledged.

Received: ((will be filled in by the editorial staff))

Revised: ((will be filled in by the editorial staff)) Published online: ((will be filled in by the editorial staff))

\section{References}

[1] J. Wu, D. Xiao, J. Zhu, Chem. Rev. 2015, 115, 2559.

[2] B. Lei, C. Li, D. Zhang, Q. F. Zhou, K. K. Shung, C. Zhou, Appl. Phys. Lett. 2004, 84, 4553.

[3] A. Castro, P. Ferreira, P. M. Vilarinho, J. Phys. Chem. C 2016, 120, 10961.

[4] M. Lallart, Ferroelectrics - Material Aspects, IntechOpen, London, UK 2011.

[5] N. Nuraje, K. Su, Nanoscale 2013, 5, 8752.

[6] Q. Zhang, N. Valanoor, O. Standard, J. Mater. Chem. C 2015, 3, 582.

[7] G. Ray, N. Sinha, B. Singh, I. Bdikin, B. Kumar, Cryst. Growth Des. 2015, 15, 1852.

[8] Q. Deng, J. Zhang, T. Huang, L. Xu, K. Jiang, Y. Li, Z. Hu, J. Chu, J. Mater. Chem. C 2015, 3, 8225 .

[9] M.-H. Zhang, K. Wang, Y.-J. Du, G. Dai, W. Sun, G. Li, D. Hu, H. Cheng Thong, C.

Zhao, X.-Q. Xi, Z.-X. Yue, J.-F. Li, J. Am. Chem. Soc. 2017, 139, 3889.

[10] M. Yashima, S. Matsuyama, J. Phys. Chem. C 2012, 116, 24902.

[11] S. Sanna, W. Gero Schmidt, Phys. Rev. B 2010, 81, 214116.

[12] K. Cordero-Edwards, N. Domingo, A. Abdollahi, J. Sort, G. Catalan, Adv. Mater. 2017, 29, 1702210. 


\section{WILEY-VCH}

[13] D. Lee, H. Xu, V. Dierolf, V. Gopalan, S. R. Phillpot, Appl. Phys. Lett. 2011, 98, 092903.

[14] A. Savage, J. Appl. Phys. 1966, 37, 3071.

[15] V. Gopalan, T. E. Mitchell, Y. Furukawa, K. Kitamura, Appl. Phys. Lett. 1998, 72, 1981.

[16] V. Gopalan, M. C. Gupta, Ferroelectrics 1997, 198, 49.

[17] Y. S. Shin, M. Yoshida, Y. Akiyama, N. Imaishi, S. C. Jung, Jpn. J. Appl. Phys. 2003, $42,5227$.

[18] Y. Shibata, K. Kaya, K. Akashi, M. Kanai, T. Kawai, S. Kawai, Appl. Phys. Lett. 1992, 61, 1000.

[19] J.-W. Son, S. S. Orlov, B. Phillips, L. Hesselink, J. Electroceram. 2006, 17, 591.

[20] E. Østreng, H. H. Sønsteby, T. Sajavaara, O. Nilsen, H. Fjellvåg, J. Mater. Chem. C 2013, $1,4283$.

[21] M. Brooks Tellekamp, J. C. Shank, M. S. Goorsky, W. A. Doolittle, J. Electron. Mater. 2016, 45, 6292.

[22] S. Schwyn, H. W. Lehmann, R. Widmer, J. Appl. Phys. 1992, 72, 1154.

[23] L. W. Martin, A. M. Rappe, Nat. Rev. Mater. 2016, 2, 16087.

[24] Y. Zhang, J. Roscow, R. Lewis, H. Khanbareh, V. Yu Topolov, M. Xie, C. R. Bowen, Acta Mater. 2018, 154, 100.

[25] R. Khachaturyan, S. Zhukov, J. Schultheiß, C. Galassi, C. Reimuth, J. Koruza, H. von Seggern, Y. A. Genenko, J. Phys. D: Appl. Phys. 2017, 50, 045303.

[26] G. A. Ozin, K. Hou, B. V. Lotsch, L. Cademartiri, D. P. Puzzo, F. Scotognella, A. Ghadimi, J. Thomson, Mater. Today 2009, 12, 12.

[27] M. C. Orilall, U. Wiesner, Chem. Soc. Rev. 2011, 40, 520.

[28] M. Rawolle, M. A. Niedermeier, G. Kaune, J. Perlich, P. Lellig, M. Memesa, Y.-J. Cheng, J. S. Gutmann, P. Müller-Buschbaum, Chem. Soc. Rev. 2012, 41, 5131. 


\section{WILEY-VCH}

[29] P. Innocenzi, L. Malfatti, Chem. Soc. Rev. 2013, 42, 4198.

[30] Y. Deng, J. Wei, Z. Sun, D. Zhao, Chem. Soc. Rev. 2013, 42, 4054.

[31] D. Gu, F. Schüth, Chem. Soc. Rev. 2014, 43, 313.

[32] Y. Ren, Z. Ma, P. G. Bruce, Chem. Soc. Rev. 2012, 41, 4909.

[33] N. D. Petkovich, A. Stein, Chem. Soc. Rev. 2013, 42, 3721.

[34] M. Niederberger, N. Pinna, J. Polleux, M. Antonietti, Angew. Chem. Int. Ed. 2004, 43, 2270.

[35] P. Ferreira, R. Z. Hou, A. Wu, M.-G. Willinger, P. M. Vilarinho, J. Mosa, C. LabertyRobert, C. Boissière, D. Grosso, C. Sanchez, Langmuir 2012, 28, 2944.

[36] J. Roscow, Y. Zhang, J. Taylor, C. R. Bowen, Eur. Phys. J. Special Topics 2015, 224, 2949.

[37] C. Reitz, P. M. Leufke, H. Hahn, T. Brezesinski, Chem. Mater. 2014, 26, 2195.

[38] Y. Lu, R. Ganguli, C. A. Drewien, M. T. Anderson, C. J. Brinker, W. Gong, Y. Guo, H. Soyez, B. Dunn, M. H. Huang, J. I. Zink, Nature 1997, 389, 364.

[39] C. J. Brinker, Y. Lu, A. Sellinger, H. Fan, Adv. Mater. 1999, 11, 579.

[40] D. Grosso, F. Cagnol, G. J. de A. A. Soler-Illia, E. L. Crepaldi, H. Amenitsch, A. Brunet-Bruneau, A. Bourgeois, C. Sanchez, Adv. Funct. Mater. 2004, 14, 309.

[41] A. Thomas, H. Schlaad, B. M. Smarsly, M. Antonietti, Langmuir 2003, 19, 4455.

[42] B. M. Smarsly, D. Grosso, T. Brezesinski, N. Pinna, C. Boissière, M. Antonietti, C. Sanchez, Chem. Mater. 2004, 16, 2948.

[43] A. S. Deshpande, N. Pinna, B. M. Smarsly, M. Antonietti, M. Niederberger, Small, 2005, $1,313$.

[44] T. Brezesinski, J. Wang, S. H. Tolbert, B. Dunn, J. Sol-Gel Sci. Technol. 2011, 57, 330.

[45] C. Weidmann, K. Brezesinski, C. Suchomski, K. Tropp, N. Grosser, J. Haetge, B. M. Smarsly, T. Brezesinski, Chem. Mater. 2012, 24, 486. 


\section{WILEY-VCH}

[46] E. Ortel, A. Fischer, L. Chuenchom, J. Polte, F. Emmerling, B. M. Smarsly, R. Kraehnert, Small 2012, 8, 298.

[47] B. Eckhardt, E. Ortel, J. Polte, D. Bernsmeier, O. Görke, P. Strasser, R. Kraehnert, Adv. Mater. 2012, 24, 3115.

[48] C. Reitz, C. Suchomski, J. Haetge, T. Leichtweiss, Z. Jagličić, I. Djerdj, T.

Brezesinski, Chem. Commun. 2012, 48, 4471.

[49] C. Díaz Valenzuela, G. A. Carriedo, M. L. Valenzuela, L. Zúñiga, C. O'Dwyer, Sci. Rep. 2013, 3, 2642.

[50] P. M. Leufke, R. Kruk, R. A. Brand, H. Hahn, Phys. Rev. B 2013, 87, 094416.

[51] K. Rabe, M. Dawber, C. Lichtensteiger, C. Ahn, J. Triscone, Modern Physics of Ferroelectrics: Essential Background, In: Physics of Ferroelectrics. Topics in Applied Physics, Springer, Berlin, Heidelberg, 2007.

[52] A. N. Morozovska, E. A. Eliseev, N. V. Morozovsky, S. V. Kalinin, Phys. Rev. B 2017, 95, 195413.

[53] K. Kaemmer, H. Huelz, B. Holzapfel, W. Haessler, L. Schultz, J. Phys. D: Appl. Phys. 1997, 30, 522 .

[54] J. F. Scott, C. A. Araujo, B. M. Melnick, L. D. McMillan, R. Zuleeg, J. Appl. Phys. 1991, 70, 382 . 


\section{WILEY-VCH}
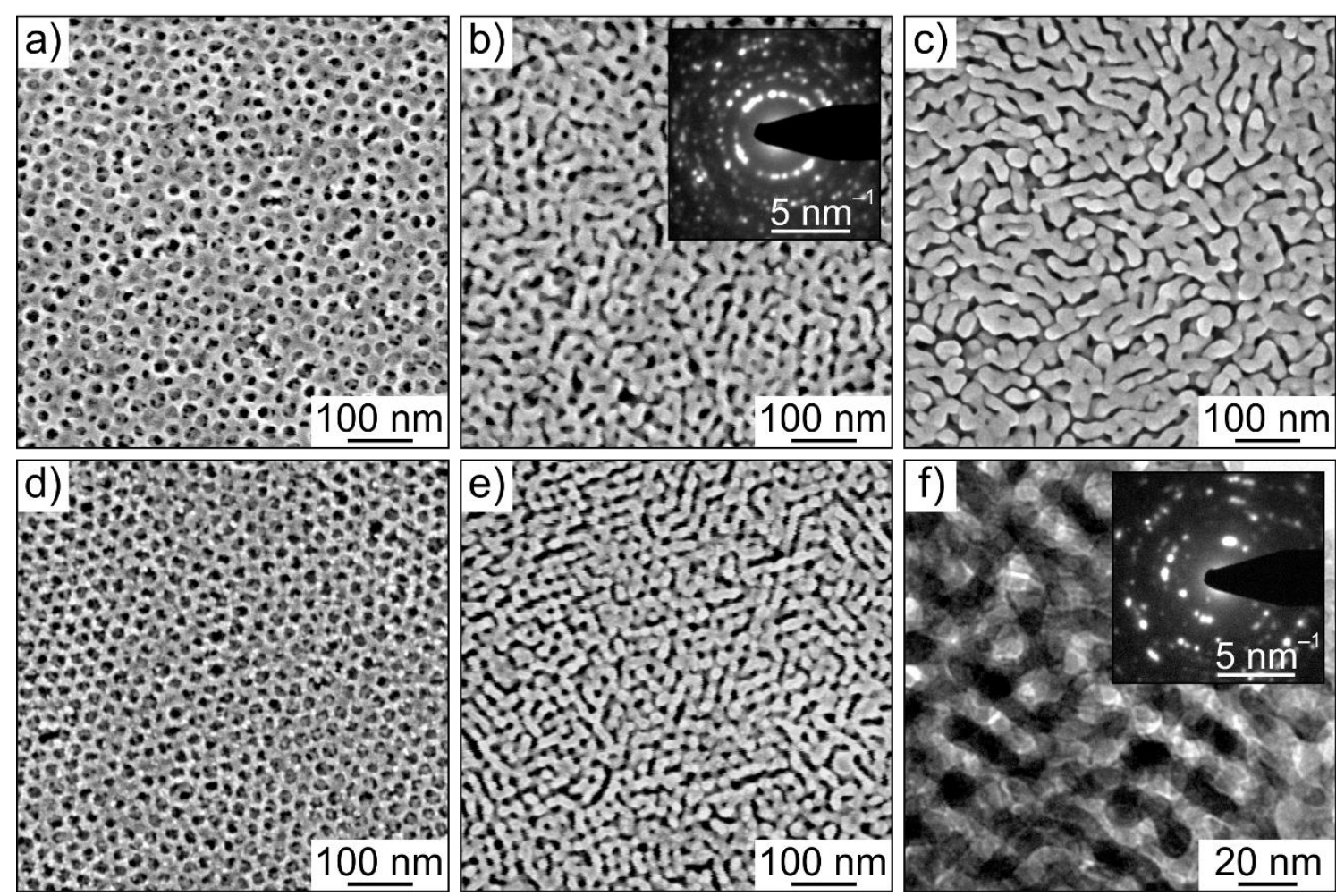

Figure 1. Electron microscopy of (a-c) mesoporous $\mathrm{LiNbO}_{3}$ and (d-f) $\mathrm{LiTaO}_{3}$ thin films heated at (a and d) $500{ }^{\circ} \mathrm{C}$, (b) $600{ }^{\circ} \mathrm{C}$, (c) $650{ }^{\circ} \mathrm{C}$, and (e and f) $700{ }^{\circ} \mathrm{C}$. (a-e) Top-view SEM images. (f) Bright-field TEM image. The insets in parts $b$ and $f$ are ED patterns of the same samples. The red arrow indicates the increase in heating temperature in the case of $\mathrm{LiNbO}_{3}$.
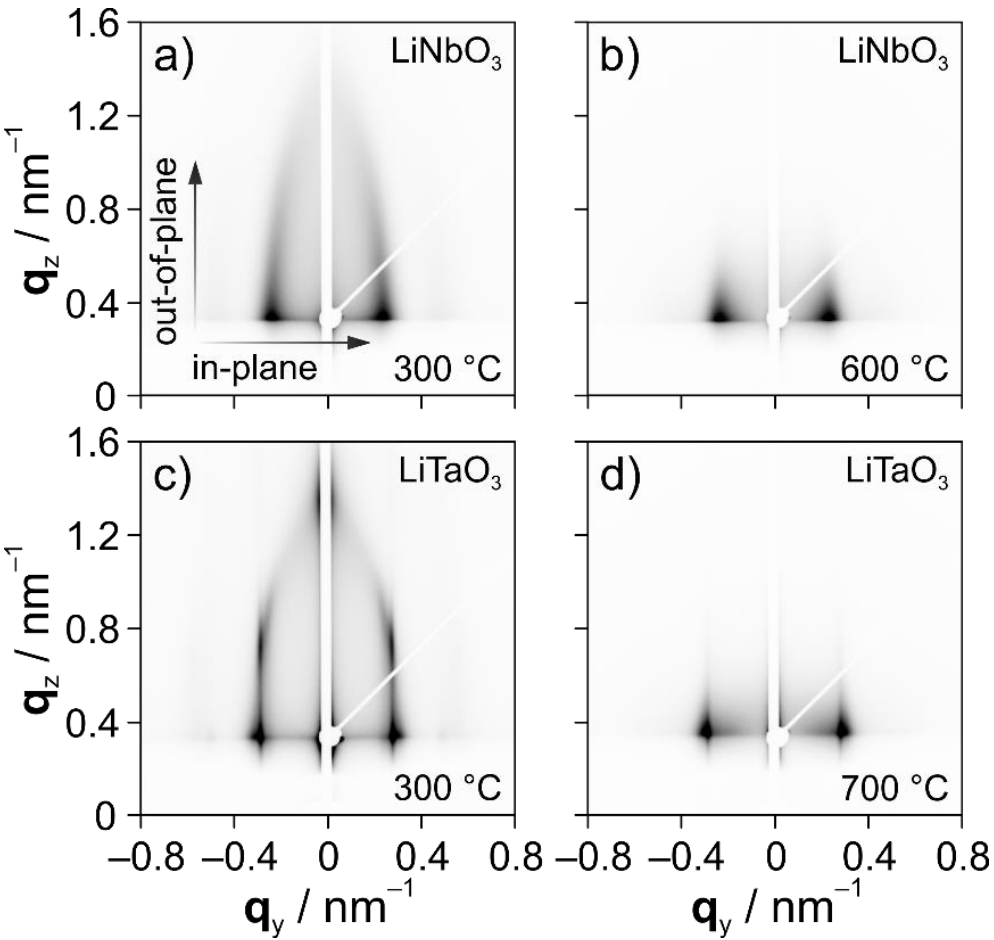

Figure 2. Synchrotron-based GISAXS patterns at $0.2^{\circ}$ incidence angle for ( $a$ and $b$ ) mesoporous $\mathrm{LiNbO}_{3}$ and (c and d) $\mathrm{LiTaO}_{3}$ thin films in amorphous and crystalline states. 

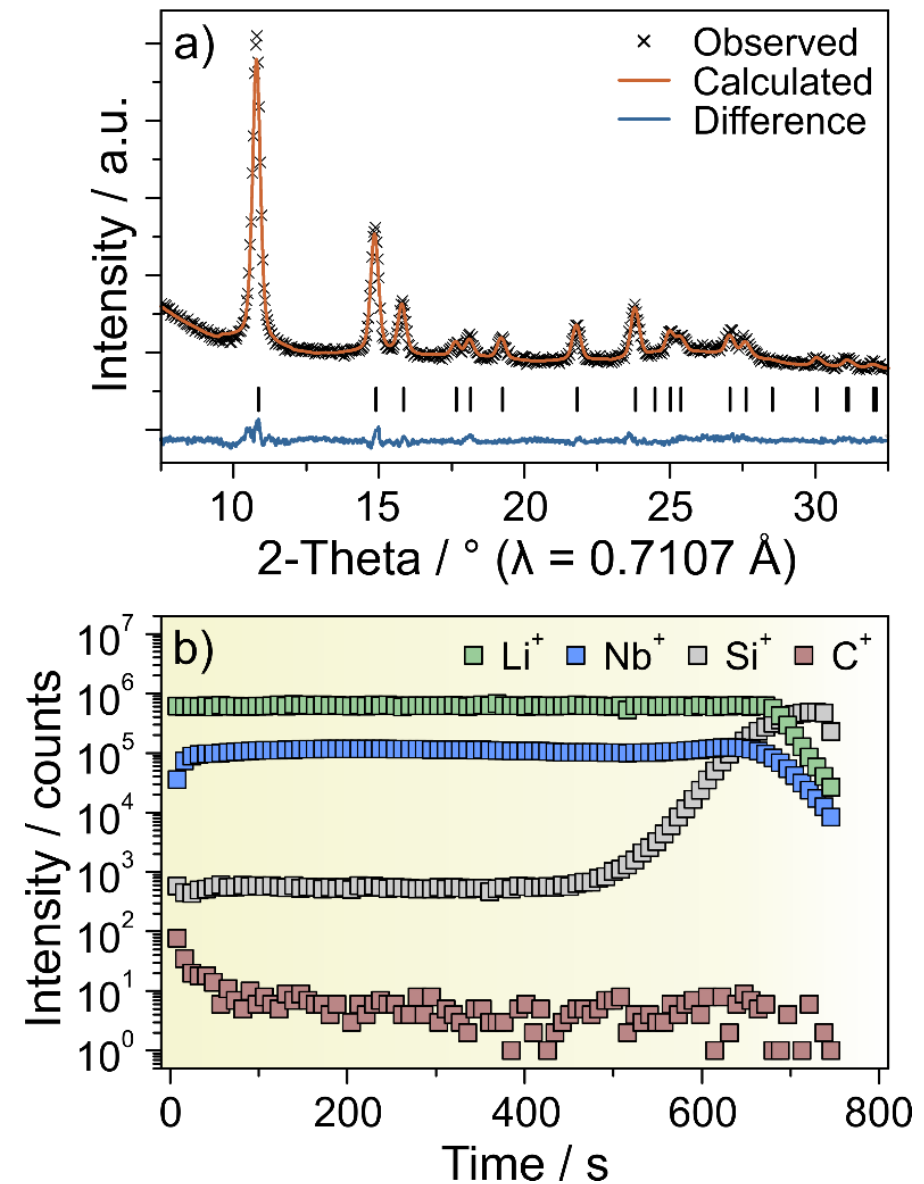

Figure 3. (a) Rietveld plot for GIXD data obtained on a mesoporous $\mathrm{LiNbO}_{3}$ thin film heated at $650{ }^{\circ} \mathrm{C}$. The vertical ticks indicate the expected Bragg positions for ferroelectric $\mathrm{LiNbO}_{3}$. The fit to the data is good, with $R_{\mathrm{wp}}$ and $\chi^{2}$ being 7.99 and 1.81, respectively. (b) ToF-SIMS depth profiling showing ${ }^{7} \mathrm{Li}^{+},{ }^{93} \mathrm{Nb}^{+},{ }^{28} \mathrm{Si}^{+}$, and ${ }^{12} \mathrm{C}^{+}$. The shaded area represents the film region. 

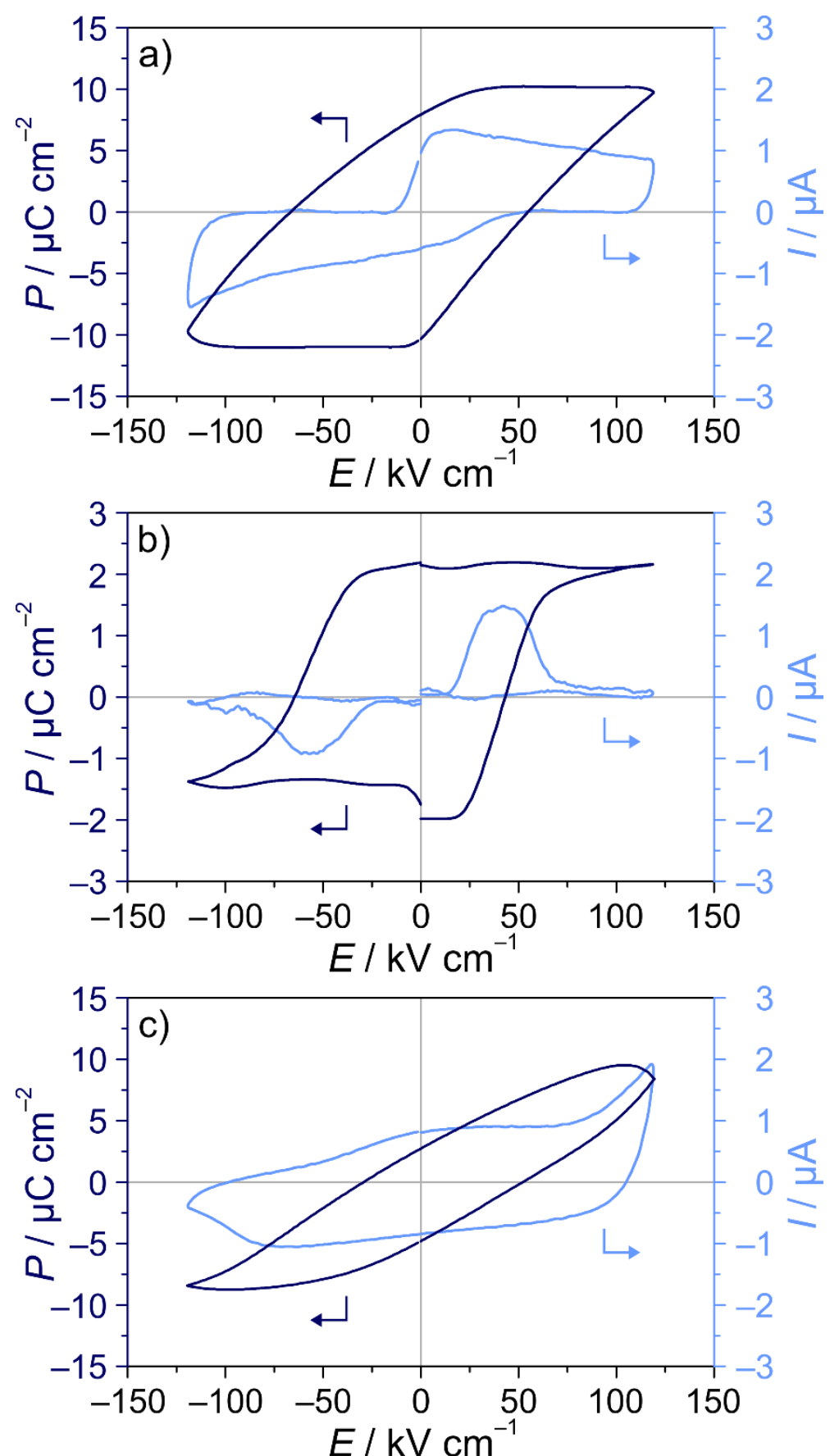

Figure 4. Room temperature ferroelectric polarization of mesoporous $\mathrm{LiNbO}_{3}$ thin films on STO:Nb substrate using ( $\mathrm{a}$ and b) Au and (c) ITO top electrodes. (a and c) Dynamic and (b) remanent hysteresis loops and the corresponding current response for $10 \mathrm{~Hz}$ switching frequency. 


\section{WILEY-VCH}

Ferroelectric $\mathrm{LiNbO}_{3}, \mathrm{LiTaO}_{3}$, and solid solution $\mathrm{LiNbO}_{3}-\mathrm{LiTaO}_{3}$ were successfully produced as continuous cubic mesoporous thin films of high crystallinity by the dip-coating method using a facile coassembly strategy. Remanent polarization measurements conducted at ambient conditions on the sol-gel derived $\mathrm{LiNbO}_{3}$ material demonstrated a stable and robust (macroscopic) switching polarization.

Sol-gel chemistry, polymer templating, lithium niobate, lithium tantalate, ferroelectricity

L. Androš Dubraja,* R. Kruk, T. Brezesinski*

Robust Macroscopic Polarization of Block Copolymer-Templated Mesoporous Perovskite-Type Thin-Film Ferroelectrics

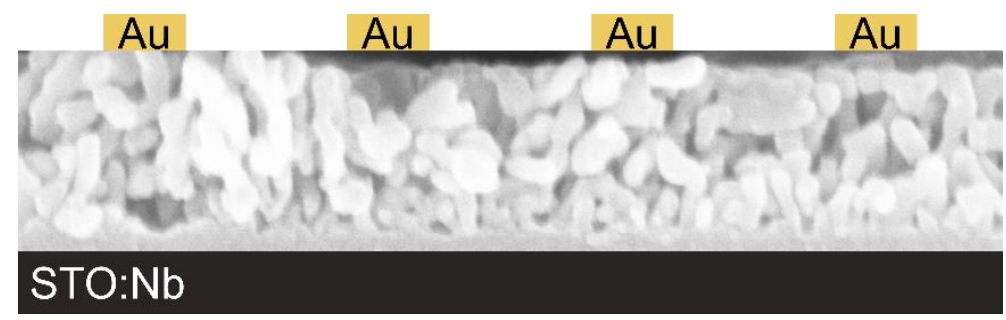

